\title{
In-vitro activity of lipoic acid against Ureaplasma urealyticum and Ureaplasma parvum isolated from women with infections of the urogenital tract. A pilot study
}

\author{
Małgorzata Biernat-Sudolska1, Danuta Rojek-Zakrzewska and Anna Bilska-Wilkosz²⿴ \\ ${ }^{1}$ Chair of Microbiology, Jagiellonian University, Medical College, Kraków, Poland; ${ }^{2}$ Chair of Medical Biochemistry, Jagiellonian University, Medical \\ College, Kraków, Poland
}

\begin{abstract}
Several species of Ureaplasma bacteria are known to be present in the urogenital tract of humans, in both healthy individuals and symptomatic patients. These pathogens are associated with urogenital tract infections, infertility problems and spontaneous abortion in humans. The present study involved 77 strains of Ureaplasma species (Ureaplasma spp.), including 21 Ureaplasma urealyticum (U. urealyticum) strains and 56 Ureaplasma parvum (U. parvum) strains. Lipoic acid (LA) and its reduced form dihydrolipoic acid (DHLA) are synthesized in all prokaryotic and eukaryotic cells. Research of recent years increasingly points to therapeutic properties of exogenously supplemented LA. In our study, we examined for the first time the effect of LA on the bacteria multiplication and its bactericidal activity against $U$. urealyticum and $U$. parvum. The LA concentrations used were: $1200 \mu \mathrm{g} / \mathrm{ml}, 120 \mu \mathrm{g} / \mathrm{ml}$, and $12 \mu \mathrm{g} / \mathrm{ml}$. The titer for each strain of Ureaplasma spp. was estimated using the color changing units (CCU) assay. For CCU measurements, a series of 10 -fold dilutions of each cell culture in $0.9 \% \mathrm{NaCl}$ (titration) was prepared and $1 \mathrm{CCU} /$ $\mathrm{ml}$ was defined as the highest dilution of cells at which color change was detected. The strongest bacteriostatic and bactericidal effect of LA was observed at a concentration of $1200 \mu \mathrm{g} / \mathrm{ml}$. In contrast, at lower LA concentrations, stimulation of the bacteria multiplication was noted for $14 \%$ of the total number of strains tested. Taken together, the current data provide novel findings about potential beneficial antimicrobial effects of LA.
\end{abstract}

Key words: Ureaplasma urealyticum, Ureaplasma parvum, lipoic acid Received: 06 July, 2020; revised: 04 September, 2020; accepted: 19 September, 2020; available on-line: 17 December, 2020

『e-mail: anna.bilska@uj.edu.pl

Acknowledgments of Financial Support: This work was supported by statutory funds K/ZDS/008402 of the Faculty of Medicine, Jagiellonian University Medical College, Kraków, Poland.

Abbreviations: CCAL, chitosan-coated liposome containing coenzyme Q10 and lipoic acid; CCU, color changing units; E. coli, Escherichia coli; LA, lipoic acid; DHLA, dihydrolipoic acid; ROS, reactive oxygen species; S. aureus, Staphylococcus aureus; Ureaplasma spp., Ureaplasma species; U. parvum (Up), Ureaplasma parvum; U. ureaIyticum (Uu), Ureaplasma urealyticum

\section{INTRODUCTION}

The Ureaplasma genus is the second of two genera of bacteria belonging to the family Mycoplasmataceae in the order Mycoplasmatales. In 1967, the order Mycoplasmatales was incorporated into the class Mollicutes. Ureaplasma species (Ureaplasma spp.) are unique among the Mollicutes because they possess a very potent urease which hy- drolyzes urea to generate ATP and produces ammonia as a product. The Ureaplasma spp. have a genome size ranging from 0.76 to 1.17 million base pairs with a GC content of 27 to $30 \%$ and require cholesterol for growth (Razin et al., 1998).

Ureaplasma spp. are known to be present in the urogenital tract of males and females, in both healthy individuals and symptomatic patients. Fourteen known Ureaplasma serovars have been divided into two species based on phenotypic and genotypic characteristics: Ureaplasma parvum (U. parvum; Up) and Ureaplasma urealyticum (U. urealyticum; Uu) (Marovt et al., 2015). Uropathogens colonize the urogenital tract mainly via the ascending route. Given the anatomical differences in the structure of the urogenital tract of women and men, it is understandable that Ureaplasma spp. are more often identified in women than in men. Epidemiological data indicate that nearly $90 \%$ of sexually active healthy women are carriers of Ureaplasma spp. (Kim et al., 2014). Thus, it is believed that Ureaplasma spp. as a component of the microbiota of the human urogenital tract are commensal organisms of low virulence. For that reason, the presence of $U$. urealyticum and $U$. parvum can be considered not only as an infection but also as colonization (McCormack \& Rein, 2005).

However, it should be noted that Ureaplasma spp. do not cause symptoms if they live in balance with other bacteria. If the population of these microorganisms in the urogenital tract is greater than $10^{4}$ per $\mathrm{ml}$ certain health problems may develop and cause symptoms, if left untreated, can lead to serious consequences. There is strong evidence from experimental animal and clinical studies that these pathogens are associated with urogenital tract infections, infertility problems and spontaneous abortion in humans. Ureapasma spp. can cause the amniotic sac inflammation resulting in chorioamnionitis, preterm labor and neonatal lung injury. These pathogens appear to also have an etiological role in postpartum infections of mothers and newborns (Kilıç et. al. 2004; Liu et. al. 2014; Waites et. al. 2009; Zhang et. al., 2014).

Treatment of Ureaplasma infections is exceedingly difficult. The lack of a cell wall confers resistance to all $\beta$-lactam and glycopeptide antibiotics. On the other hand, the lack of de novo synthesis of folic acid makes the cells resistant to diaminopyrimidines and sulfonamides (Beeton \& Spiller, 2016; Tantengco \& Yanagihara, 2019). Many authors emphasize that the development of resistance of Ureaplasma spp. to tetracycline, fluoroquinolone and macrolides has also been observed (Beeton et al., 2009; Biernat-Sudolska et al., 2007; Saraçoğlu et al., 2018). 
Thus, it is reasonable to look for new compounds supporting the therapy of patients with infections of the urogenital tract caused by Ureplasma spp. We chose lipoic acid (LA) for our research. LA (1,2-dithiolane3 -pentanoic acid) and its reduced form dihydrolipoic acid (DHLA; 6,8-dimercaptooctanoic) are present in all prokaryotic and eukaryotic cells. In humans and other mammals, LA/DHLA system is essential for oxidation of glucose, other carbohydrates, amino acids and other fuels, and is implicated in the regulation of mitochondrial redox balance. Namely, LA/DHLA system functions as a cofactor essential for five redox reactions: four catalyzed by 2-oxoacid dehydrogenases and the glycine cleavage system. These enzymes include $\alpha$-ketoglutarate dehydrogenase and pyruvate dehydrogenase from the energy metabolism, branched-chain ketoacid dehydrogenase, 2-oxoadipate dehydrogenase, and glycine cleavage system from the amino acid metabolism. Research of recent years increasingly points to therapeutic properties of exogenously supplemented LA. Currently LA has been shown to be beneficial in type 1 and 2 diabetes by preventing the various pathologies associated with diabetes such as macular degeneration, cataracts, and neuropathy. In many clinical trials LA has been used at a dose between 300-1800 milligrams per day for diabetes and neuropathy (Dworacka et al., 2012; Evans and Goldfine, 2000). Research is also increasingly pointing to LA as an effective drug in the therapy of many diseases other than diabetes and its complications (Bast \& Haenen, 2003; Biewenga et al., 1997; Bilska and Włodek, 2005; Goraca et al., 2011; Packer et al., 1995; Skibska et al., 2015).

In our study, we examined for the first time the bacteriostatic (effects on the cell division) and bactericidal activity of LA against $U$. urealyticum and $U$. parrum.

\section{MATERIALS AND METHODS}

General. Ureaplasma strains isolated in the Chair of Microbiology of the Jagiellonian University Medical College (Kraków, Poland) from women with infections of the urogenital tract were tested in the study. The study involved 77 strains of Ureaplasma spp. including 21 $U$. urealyticum strains and $56 U$. parrum strains.

Detection of Ureaplasma spp. The vaginal swabs were collected from each woman and placed in BioMerieux transport media. Next, they were subcultured in liquid and solid PPLO media with 1\% urea, prepared in-house and parallelly in Mycoplasma IST 2 kit BioMerieux medium (R2) (BioMerieux, Marcy L'etoile, France). Liquid media and BioMerieux medium test strips were incubated for $72 \mathrm{~h}$ at $37^{\circ} \mathrm{C}$. Development of a clear red color of samples indicated the growth of Ureaplasma strains since hydrolysis of urea with the release of ammonia was signaled by a color change of a $\mathrm{pH}$ indicator. Solid media were incubated for $5-7$ days at $37^{\circ} \mathrm{C}$. In the case of solid media, it was the presence of characteristic brownish colonies that was indicative of Ureaplasma spp. (magnification $125 \times$ ).

Isolation of DNA of Ureaplasma spp. After incubation, crude Ureaplasma DNA was isolated from R2 medium by means of centrifugation and denaturation of the sediment in $100 \mu \mathrm{l}$ of sterile, distilled water at $95^{\circ} \mathrm{C}$.

PCR with species-specific primers. The identity of $U$. parvum and U. urealyticum was confirmed by amplification of the genome specific regions of these two Ureaplasma spp. Primers for U. parum and for U. urea- lyticum were: UPS2c and UPA2c (420 bp), and UUS2c, UUA2c (420 bp), respectively (Kong et al., 2000). DNA from reference strains was used as a positive control for identification of $U$. urealyticum and $U$. parvum: serotype IV ATCC 27816 and serotype III ATCC 27815, respectively. Negative control consisted of distilled water. The amplified products were visualized under ultraviolet light after agarose gel electrophoresis containing ethidium bromide (EtBr).

The effect of LA on Ureaplasma spp. In the present study, we used the formulation Thiogamma Turbo-Set (Wörwag Pharma, Germany), which contains the racemic LA mixture as a pharmacologically active substance and is used for treatment of diabetes and diabetic neuropathy. The effects of three LA concentrations: $1200 \mu \mathrm{g} / \mathrm{ml}, 120 \mu \mathrm{g} / \mathrm{ml}$ and $12 \mu \mathrm{g} / \mathrm{ml}$ on the growth and survival of Ureaplasma strains were studied. The highest concentration of $1200 \mu \mathrm{g} / \mathrm{ml}$ used in the studies was also the highest non-toxic concentration of LA for cell culture of the RK13 line, which was previously determined in in vitro studies. The titer for each Ureaplasma strain was estimated using the color changing units (CCU) assay. For CCU measurements, a series of 10 -fold dilutions of each cell culture in $0.9 \% \mathrm{NaCl}$ (titration) was prepared and $1 \mathrm{CCU} / \mathrm{ml}$ was defined as the highest dilution of cells at which color change was detected. The titre was considered to be the highest dilution which produced a color change, when the test result was recorded at a time when color changes were no longer progressive (Poveda \& Nicholas, 1998).

In our study, the 18-24-hour bacterial cultures in the growth medium in the absence of LA (control) were titrated by making 10 -fold serial dilutions $\left(10^{-1}\right.$ to $\left.10^{-10}\right)$. Titration was carried out in 96-well plates. The titer was read after 24 hours of incubation at $37^{\circ} \mathrm{C}$ and expressed as $\mathrm{CCU} / \mathrm{ml}$.

\section{Test System (two variants)}

Bacteriostatic effect of LA (on the cell division). The cultures of each Ureaplasma strain were titrated by making 10 -fold serial dilutions $\left(10^{-1}\right.$ to $\left.10^{-10}\right)$ in growth medium with the addition of the tested LA concentrations. Titration was carried out in 96-well plates. The titers were read after 24 hours of incubation at $37^{\circ} \mathrm{C}$ and expressed as $\mathrm{CCU} / \mathrm{ml}$. The obtained values were compared with the control titer for a given strain.

Bactericidal activity of LA. The culture of each Ureaplasma strain was suspended in medium with the tested concentrations of LA and was incubated for 24 hours at $37^{\circ} \mathrm{C}$. After incubation, LA was washed away with physiological saline twice by centrifugation and then titration was performed by making 10 -fold serial dilutions $\left(10^{-1}\right.$ to $\left.10^{-10}\right)$ with growth medium without the addition of LA. Titration was carried out in 96 well plates. The titer was read after 24 hours of incubation at $37^{\circ} \mathrm{C}$ and expressed as $\mathrm{CCU} / \mathrm{ml}$. The obtained values were compared with the control titer for a given strain.

Statistical analysis. Statistical calculations were carried out with the STATISTICA 12.0 software (Statsoft Inc., Tulsa, OK, USA). The differences between groups (the comparison of control titers of strains and titers achieved after 24 hours incubation with the test LA concentration) have been analyzed using nonparametric tests: ANOVA rank Kruskal-Wallis test and the chi square test $\left(\chi^{2}\right)$. A level of $p \leq 0.001$ was adopted to indicate statistical significance. 


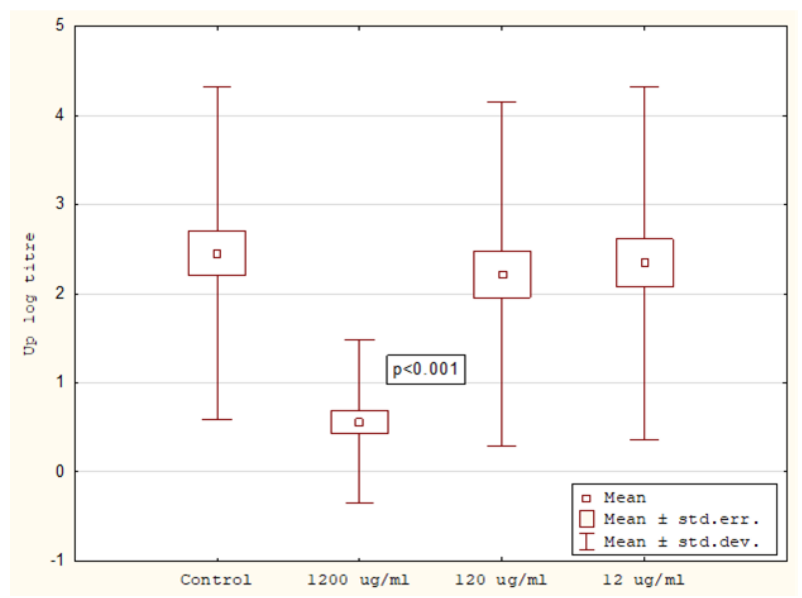

Figure 1. The effect of LA on the cell division of U. parvum" (Up). The graph shows the dependence of log titre Up on LA dose. Data are shown as the mean \pm standard deviation. $P<0.001 \mathrm{vs}$. control sample.

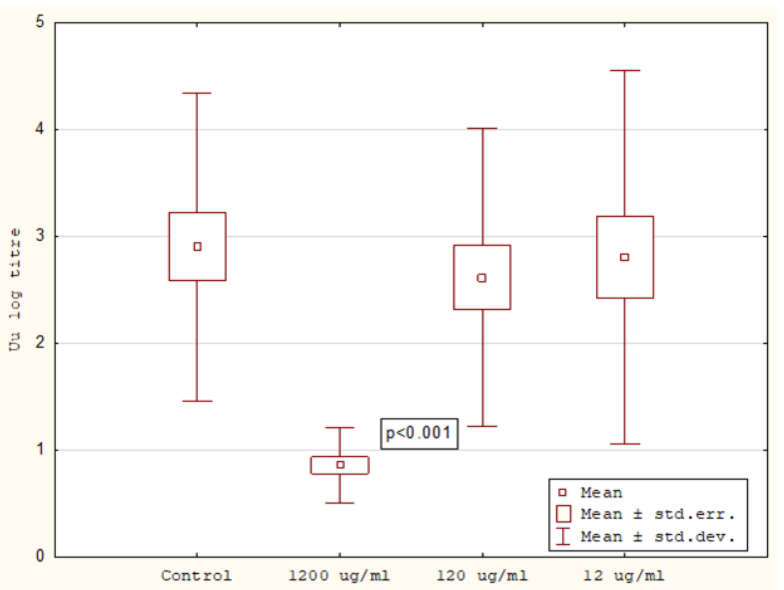

Figure 2. The effect of LA on the cell division of $U$. urealyticum (Uu).

The graph shows the dependence of log titre Uu on LA dose. Data are shown as the mean \pm standard deviation. $P<0.001$ vs. control sample.

\section{RESULTS}

\section{The effect of LA on the cell division of Ureaplasma spp.}

The obtained results indicate that LA only at the concentration of $1200 \mu \mathrm{g} / \mathrm{ml}$ had a statistically significant $(p<0.001)$ inhibitory effect on cell division of Ureaplasma strains compared to the control. Under the influence of $\mathrm{LA}$ at a concentration of $1200 \mu \mathrm{g} / \mathrm{ml}$, titer reduction by over three logarithmic (log) cycles was observed in almost $43 \%$ of $U$. parvum strains and in $28 \%$ of $U$. urealyticum strains. At lower LA concentrations $(120 \mu \mathrm{g} / \mathrm{ml}$ and $12 \mu \mathrm{g} / \mathrm{ml}$ ) the titer reduction by three log cycles was observed only in $U$. parvum and these percentages were $2.6 \%$ and $1.8 \%$, respectively (Figs 1,2 ). Inhibitory effects were observed in $94 \%$ of all U. parvum and U. urealyticum tested strains. At lower LA concentrations, the stimulation of cell division was observed for 10 strains of $U$. parvum and one strain of $U$. urealyticum which represents $14 \%$ of the total number of tested strains. Figure 3 shows the percentage of U. parvum and U. urealyti-

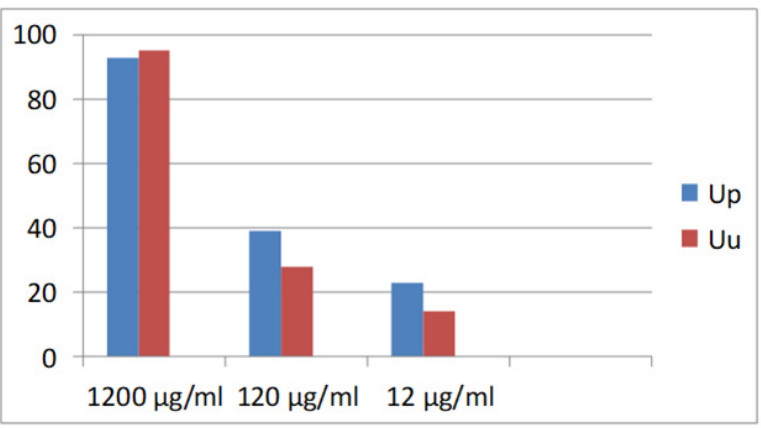

Figure 3. Percentage of $U$. parvum (Up) and $U$. urealyticum (Uu) strains for which inhibition of cell division was found at different LA concentrations.

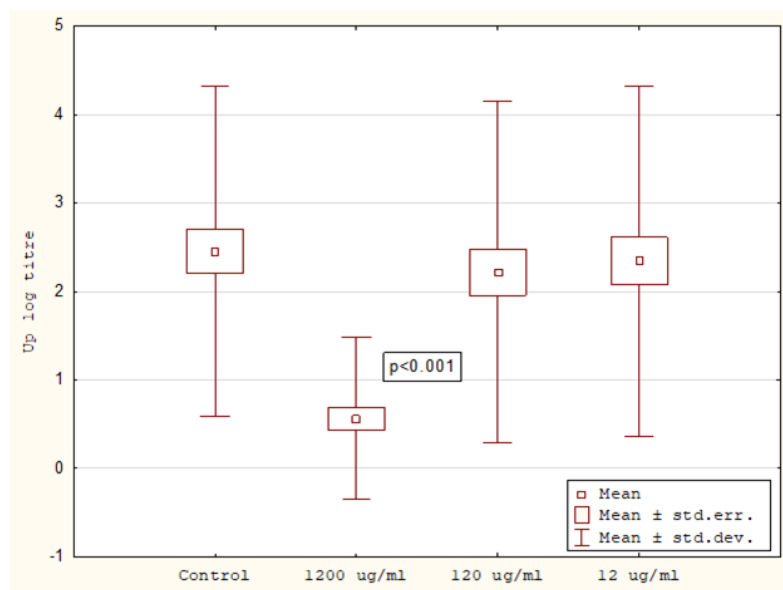

Figure 4. The bactericidal effect of LA on the U. parvum (Up) cells.

The graph shows the dependence of log titre Up on LA dose. Data are shown as the mean \pm standard deviation. $P<0.001$ vs. control sample.

cum strains for which effects of LA on the cell division were demonstrated (Fig. 3).

\section{The bactericidal effect of LA on the Ureaplasma spp.}

The strongest bactericidal effect of LA (altogether on $82 \%$ strains of $U$. urealyticum and $U$. parvum $)$ was observed at a concentration of $1200 \mu \mathrm{g} / \mathrm{ml}$. These results were statistically significant compared to the control (Figs 4, 5). A weaker bactericidal effect of LA was demonstrated for the concentrations of $120 \mu \mathrm{g} / \mathrm{ml}$ and $12 \mu \mathrm{g} / \mathrm{ml}$, respectively for $39 \%$ and $32 \%$ of the total number of strains tested. Strains belonging to the species $U$. urealyticum were more sensitive to lower LA concentrations (Figs 4, 5). Figure 6 shows the percentage of $U$. parvum and U. urealyticum strains for which bactericidal effects of LA were demonstrated (Fig. 6).

\section{DISCUSSION}

In both bacterial and eukaryotic cells, LA is synthesized in a complex multistep process. In humans, defects in the biosynthesis of LA lead to a heterogeneous group of diseases with a wide variety of clinical symptoms. There is no possibility of causal treatment of these diseases, LA supplementation is ineffective (Mayr et al., 2014; Tort et al., 2016; Yi \& Maeda, 2005). According 


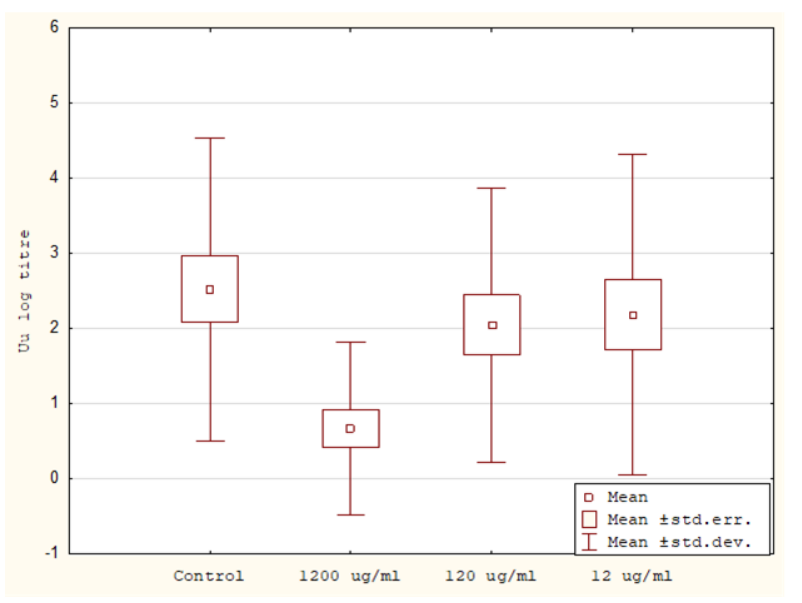

Figure 5. The bactericidal effect of LA on the U. urealyticum (Uu) cells.

The graph shows the dependence of log titre Uu on LA dose. Data are shown as the mean \pm standard deviation. $P<0.001$ vs. control sample.

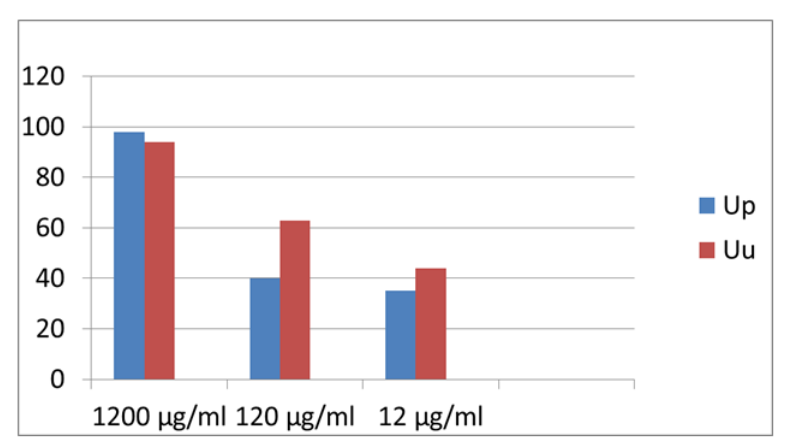

Figure 6. Percentage of $U$. parvum (Up) and U. urealyticum (Uu) strains for which bactericidal effects of LA were demonstrated.

to Hiltunen and others (Hiltunen et al., 2009) critical developmental processes require LA to be synthesized in vivo in mammalian mitochondria. Thus, in humans and generally in other eukaryotes, LA must be synthesized de novo.

It is very different in most bacterial cells which acquire LA through either de novo synthesis or scavenging from the environment (salvage), and many pathogens maintain independent LA synthesis and scavenging pathways (Spalding \& Prigge, 2010). Thus, the availability of LA in the environment should promote bacterial growth (VanLancker, 2012). Indeed, at lower LA concentrations, we observed a stimulation of proliferation for ten strains of $U$. parvum and one strain of $U$. urealyticum, which represents $14 \%$ of the total number of strains tested. However, our research has shown that LA also has antibacterial effect. At a concentration of $1200 \mu \mathrm{g} / \mathrm{ml}$, it acts as both bacteriostatic and bactericidal agent against most of the tested strains of $U$. parvum and U. urealyticum. This type of opposing effect of LA on cells depending on its dose has already been noticed. For example, Dovinova and others (Dovinova et al., 1999) in studies conducted on cultures of L1210 mouse leukemia cells, observed that LA at a concentration of $1 \mu \mathrm{M}$ increased cell proliferation, i.e., it acted as a growth factor. In contrast, at a concentration of $100 \mu \mathrm{M}$, LA acted as an antiproliferative agent. The same authors also showed that the combined single- dose administration of doxorubicin at $5 \mathrm{mg} / \mathrm{kg}$ and LA at $16 \mathrm{mg} / \mathrm{kg}$ led to a super-additive stimulating effect on survival of leukemic mice (Dovinova et al., 1999). The highest dose of LA used in our own studies on rats was $150 \mathrm{mg} / \mathrm{kg}$ divided into three doses per day (Bilska et al., 2007).

The problem of antimicrobial action of LA has rarely been studied. Many more animal studies have demonstrated that LA is highly effective in reducing endotoxin-induced cell damage and suppressing inflammatory response by inhibiting molecular signaling pathways activated by several inflammatory mediators, especially including cytokines and their receptors (Goracca \& Asłanowicz-Antkowiak, 2009; Goracca et al., 2011; Goraca et al., 2009; Li et al., 2015).

Although the problem of antimicrobial activity of LA and the mechanism of its antimicrobial action are not well recognized, there are also such data, although scarce, which confirm such LA activity. For example, it was shown that human immunodeficiency virus (HIV) replication was inhibited by LA. The study of Baur et al. indicated that a combined treatment of infected Jurkat cells with azidothymidine, a nucleoside analog inhibiting reverse transcription, and LA resulted in a stronger inhibition of HIV replication than by each drug alone (Baur et al., 1991). It is commonly known that the expression of HIV genes depends, among others, on the activity of the transcription factor NF- $x$ B. It has been shown that LA has a more potent activity in inhibiting $\mathrm{NF}-x \mathrm{~B}$, and in addition LA completely abolished the initiation of HIV-1 induction by tumor necrosis factor alpha (TNF-alpha) (Merin et al., 1996).

Also noteworthy are the research results showing that LA has a moderate antimicrobial activity against Cronobacter sakazakii strains. Those authors demonstrated that LA exerted its inhibitory effect through reduction of intracellular ATP levels in bacterial cells, causing many membrane-disrupting effects and finally increasing permeability of the cell membrane (Shi et al., 2016). In turn, Zao et al. demonstrated that chitosan-coated liposome containing coenzyme Q10 and LA (CCAL) showed a strong antimicrobial effect against Escherichia coli (E. coli) and Staphylococcus aureus (S. aureus). Those authors also showed that bactericidal effect of CCAL decreased with the decreasing of its concentration, which is also consistent with our observations (Zhao et al., 2018).

On the other hand, in the murine sepsis model caused by $S$. aureus, it was found that upon infection of mice, de novo biosynthesis or salvage of LA promoted $S$. aureus survival. However, it was also noted that when both LA biosynthesis and salvage were blocked $S$. aureus was unable to survive (Zorzoli et al., 2016).

Who is right? Many authors increasingly point out that LA is not only involved in intermediate metabolism but has many other major roles in the cell. The LA/DHLA system is characterized by one of the lowest values of the standard biological redox potential $\left(\mathrm{E}_{0}=-0.29 \mathrm{~V}\right)$. Thus, DHLA is able to reduce not only reactive oxygen species (ROS) but also oxidized forms of other antioxidants and therefore is called an antioxidant of antioxidants (Packer et al., 1995). Redox reactions are essential processes of the basic metabolism of all cells. Therefore, the mechanism of pro- and antioxidant imbalance can explain etiopathogenesis and/ or development of many apparently distant pathological conditions. 
Some authors also highlighted that LA could participate in S-thiolation of proteins according to the following equation:

Protein-(SH) $)_{2}+\mathrm{LA}-(\mathrm{SS}) \leftrightarrow$ Protein-(SH)-S-S-LA-SH $\leftrightarrow$ Protein(SS)+DHLA-(SH)

This process is perceived as a molecular "switch" decisive for intracellular redox status of thiols which controls cellular metabolic pathways (Shay et al., 2008).

One more concept, so far rarely raised by other authors, should also be mentioned. Namely, in our earlier studies we have shown that LA increases the level of sulfane sulfur in animal tissues and the activity of enzymes involved in its metabolism, although our results also showed that LA itself is a source of sulfane sulfur in vitro (Bilska et al., 2008; Bilska-Wilkosz et al., 2017). Sulfane sulfur is a divalent sulfur atom bonded to another sulfur atom. Sulfane sulfur atom is very reactive and labile. It is interesting because sulfane sulfur can modify cysteine residues in proteins via an S-Sulfhydration reaction to produce protein persulfides. This process is seen as one of the ways of covalent modification of proteins that change their activity. Sulfane sulfur is also regarded as a form of hydrogen sulfide $\left(\mathrm{H}_{2} \mathrm{~S}\right)$ storage (Iciek et al., 2019). Olson and others (Olson et al., 2020) indicated that LA increased both $\mathrm{H}_{2} \mathrm{~S}$ and polysulfide production in HEK293 cells and that this effect was sustained over several days. Zygmunt and others (Zygmunt et al., 2013) demonstrated that anti-inflammatory activity of LA in a mouse model of zymosan-induced peritonitis was associated with an increase in the level of sulfane sulfur in the peritoneal exudates.

Attempts to identify the likely mechanism of antimicrobial activity of lipoic acid against $U$. urealyticum and U. parvum led us to formulate the following hypothesis: at low concentrations of LA, the bacterial cell uses it only as a cofactor for metabolically active enzymes and LA acts as a growth factor. At higher concentrations of LA, the cell demand for LA to be used in metabolic processes has already been met and the remaining LA affects cellular proteins through the various mechanisms discussed above, which leads to changes in their activity and, as a consequence, to cell death and/or inhibition of cell proliferation. This type of opposing effect of LA on cells depending on its dose has already been noticed, however, the mechanism of these processes remains unknown. However, this is a pilot study. A detailed understanding of the molecular mechanisms of antimicrobial activity of LA requires further research, including in vivo testing.

\section{CONCLUSION}

In the present study, for the first time we examined bacteriostatic (effects on the cell division) and bactericidal activity of LA against $U$. urealyticum and U. parvum. The strongest bacteriostatic and bactericidal effect of LA was observed at a concentration of $1200 \mu \mathrm{g} / \mathrm{ml}$. In contrast, at lower LA concentrations stimulation of cell division was observed in $14 \%$ of the total number of strains tested.

Thus, the current data provide novel findings about potential beneficial, antimicrobial effects of LA. Obviously, more research is needed, especially in vivo. The biggest challenge seems to be solving the problem of the correct dosage of LA. This problem is of course extremely important for any drug, but in this case, there is an additional difficulty due to the type of opposing ef- fect of LA on cells depending on its dose, demonstrated by many authors and by us in this work.

The hypothesis linking the antimicrobial activity of LA with its influence on the transformation of sulfur compounds, as well as its participation in protein S-thiolation processes, perceived as a molecular "switch" decisive for intracellular redox status of thiols which controls cellular metabolic pathways, also requires verification.

So, we have a long way to go. Nevertheless, it can be expected that the results of the future studies will allow for the practical use of LA as a medicine supporting the maintenance of normal microbiota of the human urogenital system.

\section{Conflicts of interest}

The authors have declared no conflict of interest.

\section{REFERENCES}

Bast A, Haenen GR (2003) Lipoic acid: a multifunctional antioxidant. Biofactors 17: 207-213. https://doi.org/10.1002/biof.5520170120

Baur A, Harrer T, Peukert M, Jahn G.; Kalden JR, Fleckenstein B (1991) Alpha-lipoic acid is an effective inhibitor of human immunodeficiency virus (HIV-1) replication. Klin Wochenschr 69: 722-724. https://doi.org/10.1007/BF01649442

Beeton ML, Chalker VJ, Maxwell NC, Kotecha S, Spiller OB (2009) Concurrent titration and determination of antibiotic resistance in Ureaplasma species with identification of novel point mutations in genes associated with resistance. Antimicrob Agents Chemother 53: 2020-2027. https://doi.org/10.1128/AAC.01349-08

Beeton ML, Spiller OB (2017) Antibiotic resistance among Ureaplasma spp. isolates: cause for concern? J Antimicrob Chemoth 72: 330-337. https://doi.org/10.1093/jac/dkw425

Biernat-Sudolska M, Rojek-Zakrzewska D, Drzewiecki A, Lauterbach R (2007) Antimicrobial susceptibility of Ureaplasma urealyticum and Ureaplasma parvum isolated from premature infants with respiratory disorders. Przegl Epidemiol 61: 371-376 (in Polish)

Biewenga GP, Haenen GR, Bast A (1997) The pharmacology of the antioxidant lipoic acid. Gen Pharmac 29: 315-331. https://doi.org/ 10.1016/s0306-3623(96)00474-0

Bilska A, Dubiel M, Sokołowska-Jeżewicz M, Lorenc-Koci E, Włodek L (2007) Alpha-lipoic acid differently affects the reserpine-induced oxidative stress in the striatum and prefrontal cortex of rat brain. Neuroscience 146: 1758-1771. https://doi.org/10.1016/j.neuroscience.2007.04.002

Bilska A, Dudek M, Iciek M, Kwiecień I, Sokołowska-Jeżewicz M, Filipek B, Włodek L (2008) Biological actions of lipoic acid associated with sulfane sulfur metabolism. Pharmacol Rep 60: 225-232

Bilska A, Włodek L (2005) Lipoic acid — the drug of the future? Pharmacol Rep 57: 570-577

Bilska-Wilkosz A, Iciek M, Kowalczyk-Pachel D, Górny M, Sokołowska-Jeżewicz M, Włodek L (2017) Lipoic acid as a possible pharmacological source of hydrogen sulfide/sulfane sulfur. Molecules 22: 388. https://doi.org/10.3390/molecules22030388

Dovinova I, Novotny L, Rauko P, Kvasnicka P (1999) Combined effect of lipoic acid and doksorubicin in murine leukemia. Neoplasma 46: $237-241$

Dworacka M, Krzyżagórska E, Zielińska-Kuzemko M, Wesołowska A, Winiarska H (2012) The efficacy of $\alpha$-lipoic acid. Prz. Kardiodiabetol 7: 36-43 (in Polish)

Evans JL, Goldfine ID (2000) $\alpha$-Lipoic acid: a multifunctional antioxidant that improves insulin sensitivity in patients with type 2 diabetes. Diabetes Technol The 2: 401-413. https://doi. org/10.1089/15209150050194279

Goraca A, Asłanowicz-Antkowiak K (2009) Prophylaxis with alphalipoic acid against lipopolisaccharide-induced brain injury in rats. Arch Immunol Ther Exp (Warsz) 57: 141-146. https://doi.org/ $10.1007 /$ s00005-009-0015-z

Gorąca A, Huk-Kolega H, Piechota A, Kleniewska P, Ciejka E.; Skibska B (2011) Lipoic acid-biological activity and therapeutic potential. Pharmacol Rep 63: 849-858. https://doi.org/10.1016/s1734$1140(11) 70600-4$

Gorąca A, Piechota A, Huk-Kolega H (2009) Effect of alpha-lipoic acid on LPS-induced oxidative stress in the heart. J Physiol Pharmacol 60: 61-68.

Hiltunen JK, Schonauer MS, Autio KJ, Mittelmeier TM, Kastaniotis AJ, Dieckmann CL (2009) Mitochondrial fatty acid synthesis type II: more than just fatty acids. J Biol Chem 284: 9011-9015. https:/ / doi.org/10.1074/jbc.R800068200 
Iciek M, Bilska-Wilkosz A, Górny M (2019) Sulfane sulfur-new findings on an old topic. Acta Biochim Pol 66: 533-544. https://doi. org/10.18388/abp.2019_2909

Kilıc D, Basar MM, Kaygusuz S, Yilmaz E, Basar H, Batislam E (2004) Prevalence and treatment of Chlamydia trachomatis, Ureaplasma urealyticum, and Mycoplasma hominis in patients with nongonococcal urethritis. Jpn J Infect Dis 57: 17-20.

Kim Y, Kim J, Lee KA (2014) Prevalence of sexually transmitted infections among healthy Korean women: implications of multiplex PCR pathogen detection on antibiotic therapy. I Infect Chemother 20: 74-76. https://doi.org/10.1016/j.jiac.2013.08.005

Kong F, Ma Z, James G, Gordon S, Gilbert GL (2000) Species Identification and Subtyping of Ureaplasma parvum and Ureaplasma urealyticum Using PCR-Based Assays. J Clin Microbiol 38: 1175-1179. https://doi.org/10.1128/JCM.38.3.1175-1179.2000

Li YH, He Q, Yu JZ, Liu CY, Feng L, Chai Z, Wang Q, Zhang HZ, Zhang GX, Ma CG (2015) Lipoic acid protects dopaminergic neurons in LPS-induced Parkinson's disease model. Metab Brain Dis 30: 1217-1226. https://doi.org/ 10.1007/s11011-015-9698-5

Liu J, Wang Q, Ji, X, Guo S, Dai Y, Zhang Z, Jia L, Shi Y, Tai S, Lee Y (2014) Prevalence of Ureaplasma urealyticum, Mycoplasma bominis, Chlamydia trachomatis infections, and semen quality in infertile and fertile men in China. Urology 83: 795-799. https://doi. org/10.1016/j.urology.2013.11.009

Marovt M, Keše D, Kotar T, Kmet N, Miliković J, Šoba B, Matičič M (2015) Ureaplasma parvum and Ureaplasma urealyticum detected with the same frequency among women with and without symptoms of urogenital tract infection. Eur J Clin Microbiol Infect Dis 34: 1237-1245. https://doi.org/10.1007/s10096-015-2351-8

Mayr JA, Feichtinger RG, Tort F, Ribes A, Sperl W (2014) Lipoic acid biosynthesis defects. J Inherit Metab Dis 37: 553-563. https://doi. org/ 10.1007/s10545-014-9705-8

McCormack WM, Rein MF (2005) Urethritis. In Principles and Practice of Infectious Diseases. Mandell GL, Bennet JE, Dolin R, eds, pp 12081217. Churchill Livingstone, New York

Merin JP, Matsuyama M, Kira T, Baba M, Okamoto T (1996) $\alpha$-Lipoic acid blocks HIV-1 LTR-dependent expression of hygromycin resistance in THP-1 stable transformants. FEBS Lett 394: 9-13. https:// doi.org/10.1016/0014-5793(96)00919-2

Olson KR, Briggs A, Devireddy M, Xian, M, Gao Y (2020). Are the beneficial effects of 'antioxidant' lipoic acid mediated through metabolism of reactive sulfur species? Free Radic Biol Med 146: 139-149. https://doi.org/10.1016/j.freeradbiomed.2019.10.410

Packer L, Witt EH, Tritschler HJ (1995) Alpha-lipoic acid as a biological antioxidant. Free Radic Biol Med 19: 227-250. https://doi. org/10.1016/0891-5849(95)00017-r

Poveda JB, Nicholas R (1998) Serological identification of mycoplasmas by growth and metabolism inhibition tests. In Methods in Molecular Biology, Mycoplasma Protocols. Miles R, Nicholas R eds, pp 105-111. Humana Press Inc.

Razin S, Yogev D, Naot Y (1998) Molecular biology and pathogenicity of mycoplasmas. Microbiol Mol Biol Rev 62: 1094-1156. https://doi. org/10.1128/MMBR.62.4.1094-1156.1998
Saraçoğlu M, Eroğlu A, Divrik RT (2018) Development of antibiotic resistanceagainst ureaplasma urealyticum strains isolated from urogenital samples. J Urol Surg 5: 17-20. https://doi.org/10.4274/ jus. 1722

Shay KP, Moreau RF, Smith EJ, Hagen TM (2008) Is $\alpha$-lipoic acid a scavenger of reactive oxygen species in vivo? Evidence for its initiation of stress signaling pathways that promote endogenous antioxidant capacity. IUBMB Life 60: 362-367. https://doi.org/10.1002/ iub. 40

Shi C, Sun Y, Zhang X, Zheng Z, Yang M, Ben H, Song K, Cao Y, Chen Y, Liu X, Dong R, Xia X (2016) Antimicrobial effect of lipoic acid against Cronobacter sakazakii. Food Control 59: 352-358. https:// doi.org/10.1016/j.foodcont.2015.05.041

Skibska B, Goraca A (2015) The protective effect of lipoic acid on selected cardiovascular diseases caused by age-related oxidative stress. Oxid Med Cell Longev 2015: 313021. https://doi. org $/ 10.1155 / 2015 / 313021$

Spalding MD, Prigge ST (2010) Lipoic acid metabolism in microbial pathogens. Microbiol Mol Biol Rev 74: 200-228. https://doi. org/10.1128/MMBR.00008-10

Tantengco OAG, Yanagihara I (2019) Current understanding and treatment of intra-amniotic infection with Ureaplasma spp. J Obstet Gynaecol Res 45: 1796-1808. https://doi.org/10.1111/jog.14052

Tort F, Ferrer-Cortes X, Ribes A (2016) Differential diagnosis of lipoic acid synthesis defects. J Inberit Meta Dis 39: 781-793. https://doi. org/10.1007/s10545-016-9975-4

VanLancker JL (2012) Molecular And Cellular Mechanisms In Disease: 1: Bioenergetics · Cell Specificity ' Inborn Errors of Metabolism . Malnutrition . Calcium and Phosphorus Iron and Bile Pigments . Coagulopathies · Hormones Body Fluids and Electrolytes. Springer Science \& Business Media

Waites KB, Schelonka RL, Xiao L, Grigsby PL, Novy MJ (2009) Congenital and opportunistic infections: Ureaplasma species and Mycoplasma hominis. Semin Fetal Neonatal Med 14: 190-199. https://doi. org/10.1016/j.siny.2008.11.009

Yi X, Maeda N (2005) Endogenous production of lipoic acid is essential for mouse development. Mol Cell Biol 25: 8387-8392. https:// doi.org/10.1128/MCB.25.18.8387-8392.2005

Zhang N, Wang R, Li X, Liu X, Tang Z, Liu Y (2014) Are Ureaplasma spp. a cause of nongonococcal urethritis? A systematic review and meta-analysis. PloS One 9: e113771. https://doi.org/10.1371/journal. pone.0113771

Zhao G, Hu C, Xue Y (2017) In vitro evaluation of chitosan-coated liposome containing both coenzyme Q10 and alpha-lipoic acid: $\mathrm{Cy}$ totoxicity, antioxidant activity, and antimicrobial activity. J Cosmet Dermatol 17: 258-262. https://doi.org/10.1111/jocd.12369

Zorzoli A, Grayczyk JP, Alonzo III F (2016) Staphylococcus aureus tissue infection during sepsis is supported by differential use of bacterial or host-derived lipoic acid. PLOS Pathog 12: e1005933. https://doi. org/10.1371/journal.ppat.1005933

Zygmunt M, Dudek M, Bilska-Wilkosz A, Bednarski M, Mogilski S, Knutelska J, Sapa J (2003) Anti-inflammatory activity of lipoic acid in mice peritonitis model. Acta Pol Pharm 70: 899-904 